\title{
Imapct of systems ambiguity on guideline compliance in intensive care units
}

\author{
AP Gurses ${ }^{1 *}, Y$ Xiao $^{2}$, K Seidl $^{3}$ \\ From International Conference on Prevention \& Infection Control (ICPIC 2011) \\ Geneva, Switzerland. 29 June - 2 July 2011
}

\section{Introduction / objectives}

Health care associated infections (HAI) in intensive care units (ICU) can be significantly reduced or eliminated by increasing care providers' compliance with evidencebased guidelines. Using a human factors and systems engineering approach, we conducted a qualitative study to identify the underlying causes of non-compliance with evidence-based guidelines for preventing four types of HAI in ICUs.

\section{Methods}

We conducted semi-structured, in-depth interviews with a total 20 surgical ICU care providers including three attending physicians, two residents, six nurses, three quality improvement coordinators, two infection control practitioners, two respiratory therapists and two pharmacists. Thematic analysis of the qualitative data was performed using a grounded theory approach.

\section{Results}

A new framework called "systems ambiguity" that can be used to explain and prevent care providers' non-compliance with evidence-based guidelines emerged from the data. We define systems ambiguity as "uncertainty or vagueness that may prevent a work system from achieving its purpose." Five major types of ambiguity that can affect care providers' compliance behaviors have been identified: task ambiguity, responsibility ambiguity, expectation ambiguity, method ambiguity, and exception ambiguity.

\section{Conclusion}

Systems ambiguity framework can be used to (1) identify the underlying causes of care providers' non-compliance

${ }^{1}$ Anesthesiology and Critical Care, Som, Johns Hopkins University, Baltimore, USA

Full list of author information is available at the end of the article with guidelines aimed at preventing HAI, and (2) guide efforts for developing effective interventions aimed at improving compliance rates. Future research should focus on designing multi-faceted interventions based on the systems ambiguity framework and evaluating the impact of these interventions.

\section{Disclosure of interest}

A. Gurses Grant/Research support from AHRQ (K Award) and National Patient Safety Foundation, Y. Xiao: None declared, K. Seidl: None declared.

\section{Author details}

${ }^{1}$ Anesthesiology and Critical Care, Som, Johns Hopkins University, Baltimore, USA. ${ }^{2}$ Baylor Health Systems, Dallas, TX, USA. ${ }^{3}$ University of Maryland Medical Center, Baltimore, USA.

Published: 29 June 2011

doi:10.1186/1753-6561-5-S6-O48

Cite this article as: Gurses et al:: Imapct of systems ambiguity on guideline compliance in intensive care units. BMC Proceedings 20115 (Suppl 6):O48.

Submit your next manuscript to BioMed Central and take full advantage of:

- Convenient online submission

- Thorough peer review

- No space constraints or color figure charges

- Immediate publication on acceptance

- Inclusion in PubMed, CAS, Scopus and Google Scholar

- Research which is freely available for redistribution
C Biomed Central

C 2011 Gurses et al; licensee BioMed Central Ltd. This is an open access article distributed under the terms of the Creative Commons Attribution License (http://creativecommons.org/licenses/by/2.0), which permits unrestricted use, distribution, and reproduction in any medium, provided the original work is properly cited. 